\title{
CORRESPONDENCE
}

\section{Multiple metrics required to measure research performance}

SIR - Your Editorial 'Experts still needed' (Nature 457, 7-8; 2009) is correct in that no metric alone can substitute for expert evaluation, because no single metric (including citation counts) is correlated strongly enough with expert judgements for it to take their place. But some individual metrics, such as citation counts, are nevertheless significantly correlated with expert judgements. It is likely that a battery of multiple metrics, when considered jointly, will be even more strongly correlated.

The UK Research Assessment Exercise (RAE) provides such an opportunity, alongside the wealth of potential performance indicators that are increasingly available online. Both enable a candidate battery of metrics such as citations, co-citations, downloads, tags and growth/ decay metrics - to be systematically validated against expert judgements, field by field. The 2008 RAE has also provided data that make it possible to do this validation exercise now, across all disciplines, on an important nationwide scale. Stevan Harnad Institut des Sciences Cognitives, Université du Québec à Montréal, Montréal, Québec H3C 3P8, Canada; and School of Electronics and Computer Science, University of Southampton, Southampton SO17 1BJ, UK

e-mail:harnad@ecs.soton.ac.uk

\section{Evolution shapes systems, not just genes}

\section{SIR - In my book, Freaks of}

Nature: What Anomalies Tell Us About Development and Evolution, I argue that our understanding of biodiversity and evolutionary change is enhanced by looking beyond mutations and population genetics to consider the mechanisms, constraints and biases of development. Jerry Coyne's review of my book (Nature 457, 382-383; 2009) makes it clear that he disagrees.

Coyne argues that his perspective has been fully tested and accepted as the orthodox working model of evolution. Accordingly, he thinks that development may have little to teach us about evolution.

His sharpest criticism is that I have "short-changed orthodoxy". However, over the years many committed evolutionists including William Bateson, Gavin de Beer, Patrick Bateson, Gilbert Gottlieb, Pere Alberch, Stephen Jay Gould, Massimo Pigliucci, Robert Lickliter and Mary Jane West-Eberhard - have expressed similar misgivings about this orthodoxy. These individuals, with their deep appreciation of development, have seen the need to expand our evolutionary vision.

Contrary to Coyne's assertions, I never argue that genetics has a minor role in evolution, nor do I suggest that the evolutionary embrace of Gregor Mendel was misguided. On the contrary, in my book I repeatedly discuss the role of genes in normal and anomalous development and the capacity of genetic mutations to produce oddities.

But genes are only part of the answer. And so my argument in Freaks of Nature is that we need a more balanced approach. Throughout the book, I invoke the concept of interchangeability to explain, for example, how sex chromosomes or incubation temperature (or even both) can trigger in various species the developmental cascade of events that produce male and female.

In other words, development is a process comprising genetic and non-genetic factors, and evolution has shaped the entire system not just the genes - to produce the diversity of life forms we see around us. From this perspective, development must have a crucial role in mediating the transmission of form and behaviour from one generation to the next.

Mark S. Blumberg Department of Psychology, University of lowa, lowa City, lowa 52242, USA e-mail:mark-blumberg@uiowa.edu

\section{How objective is a definition in the subspecies debate?}

SIR - Michael Patten, in his Correspondence stating that 'subspecies' and 'race' should not be used as synonyms (Nature 457, 147; 2009), claims that subspecies "remains a useful taxonomic division that enriches our understanding of evolution and biogeography". But, as a classificatory unit, subspecies are not useful in comparative systematic and biogeographical studies because - unlike genera and families, for example - subspecies are groups of populations that are defined by hypothesized biological interactions or geographical distributions, rather than by homology (shared derived characteristics).

Patten says that his definition of subspecies is not arbitrary,

"as there are clear ways of describing a subspecies objectively". Yet there are no objective ways to describe species, let alone subspecies.

The species-concept debate is a result of many claiming to have found the 'objective' way to describe a species. So far, this has led to more than 25 species concepts. Patten's definition may therefore represent another addition to the already growing number of 'subspecies concepts'. Malte C. Ebach International Institute for Species Exploration and School of Life Sciences, College of Liberal Arts and Sciences, Arizona State University, PO Box 874501, Tempe, Arizona 85287-4501, USA

e-mail: mcebach@asu.edu

David M. Williams Department of Botany, The Natural History Museum, Cromwell Road, London SW7 5BD, UK e-mail:d.m.williams@nhm.ac.uk

\section{Batteries versus biomass as a transport solution}

SIR - In his Correspondence 'Choosing between batteries or biomass to stay on the road' (Nature 457, 257; 2009), Lucien Trueb presents figures that do rough justice to the potential of the battery-powered car.

The fully electric car is five times more efficient than the hydrocarbon-guzzling alternative (D. J. C. MacKay Sustainable Energy - Without the Hot Air UIT Cambridge, 2008), which takes some of the sting from batteries' lower energy density. And the energy density Trueb quotes for petrol makes no allowance for the mass of the internal-combustion engine: replacing this half-tonne lump with its weight in batteries allows electrification without sacrificing performance. For example, a range of 350 kilometres and acceleration of 0-96 kilometres per hour in less than 4 seconds is obtainable today in commercially available all-electric vehicles for which the price tag, although high, is affordable.

If biofuels are to be the alternative, we will have to sacrifice more than $10 \%$ of the world's agricultural land to powering the world's cars, or greatly increase our production of suitable 'waste'. Even then, using bio-hydrocarbons to generate electricity in power stations is roughly twice as efficient as burning them in combustion engines.

The electrification of transport is crucial if we are to break our addiction to fossil fuels. Unlike biofuels, electricity production can be scaled up to keep pace with increased car usage. Electric cars are the only long-term solution to comfortable personal transportation.

Martin Smith Department of Palaeontology, Royal Ontario Museum, 100 Queen's Park, Toronto, Ontario M5S 2C6, Canada e-mail:martins@rom.on.ca 